\title{
The acquisition of mental verbs: A systematic investigation of the first reference to mental state
}

\author{
MARILYN SHATZ* \\ HENRY M. WELL.iviÁN \\ SHARON SILBER
}

University of Michigan

\begin{abstract}
It is generally recognized that the ability to contemplate and communicate about the knowledge, beliefs, and goals of oneself and others is a benchmark of human cognition. Yet, little is known about the beginnings of this ability, in large measure because methods for accurately assessing very young children's ability have been unavailable. Here we present the results of using a method of convergent analyses of naturally occurring speech to assess the young child's ability to contemplate and communicate about mental state. The first study describes the frequency and function of verbs of mental reference such as think and know in the speech of one child from 2;4 to 4;0. The second examines shorter samples of speech collected from 30 two-year-olds over a 6 month period. Results from both studies suggest that the earliest use's of mental verbs are for conversational functions rather than for mental reference. First attempts at mental reference begin to appear in some children's speech in the second half of the third year. Since most of the children studied exhibited the linguistic knowledge necessary to make reference to mental states, we conclude that the absence of such reference earlier suggests that still younger children lack awareness of such states, or at the very least, an understanding of their appropriateness as topics of conversation.
\end{abstract}

One facet of a mature concept of persons is the understanding that people possess beliefs, thoughts, and intentions that are part of their internal world,

\footnotetext{
*Order of authorship between the two senior authors is arbitrary, decided by a flip of a coin. We wish ro thank Stan Kuczaj who generously provided access to his transcripts and Nick Roomeliotis who assisted with data analysis. The research was supported by NIMH grant MH-30996 to the first author, a Spencer Fellowship to the second author, and a traineeship from NICHHD grant HD-07109 to the third author. Reprint requests should be sent to either Marilyu Shatz or Henry Wellman, Department of Psychology, University of Michigan. Ann Arbor, MI 48109, U.S.A.
} 
distinet from the world of observable behavior and physical events. Although researchers have investigated understandings of the mental world in children as young as four (see Wellman, in press), the beginnings of such understandings are essentially unknown. Basic issues still remaining include the question of when children begin to differentiate mental states and processes from external behaviors and events, the nature of these early differentiations, and the sorts of precursors they may have.

Investigating these issues for very young children presents a particularly difficult problem. Virtually all studies examining children's knowledge of the mental domain use language as the medium of assessment. For young children, one must ask whether language is an appropriate medium for accurate assessment or whether evidence of early understanding of the internal world may be misconstrued because of the child's linguistic immaturity. In this paper we present two studies using a method that, while still language-based, we believe addresses the concern for accurate early assessment.

The classic method for collecting data on knowledge of the mental world is the interview (Broughton, 1978; Piaget, 1929). More recently, methods better suited to young children have been used. One is the identification of mental terms in naturally occurring speech. From $2^{1 / 2}$ years on, children use mental terms such as think, know, and remember in their spontaneous speech (Limber, 1973). The occurrence of such lexical items might be taken as evidence that young children have a theory of mind (Bretherton et al., 1981). There are reasons however, to question such an interpretation. Adults use such terms for a variety of conversational functions, some of which do not make direct reference to a mental state. For example, there are conventional pause-fillers such as you know and phrases used to mitigate a demand, as in I think I want a cookie. These conversational uses, as we call them, are derived from the semantic properties of the verbs referring to the mental domain, yet clearly they are not intended to make specific reference to the listener's or speaker's knowledge state. Whereas adults most probably understand the indirect relation between mental reference and these conversational functions, it is questionable whether children do. Moreover, children may recruit mental terms for certain conversational functions without even an understanding or awareness of mental states themselves. The mere occurrence of a word in a child's speech does not necessarily indicate that its producer understands its semantic presuppositions. Children's early uses of words often indicate different or incomplete semantic underr innings compared to those of adults (Clark, 1978; Nelson, et al., 1978). H nce, an investigation of the child's knowledge of mental life needs to go !-yond the identification of mental terms in spontaneous speech.

One study has gone a step further by investigating how mental terms are 
used in children's speech. Gelman and Shatz (1977) found both mental reference and conversational uses in the speech of children as young as 4 years. Their method, relating form to function, has yet to be apnliced to still younger children. Even the Gelman and Shatz analysis (or the similar one of Gearhart and Hall, 1978 (Reference Note 1)) does not solve all of the problems that arise in attempting to assess younger children's knowledge. For one, their coding scheme relies on language use to display cognitive competence. Young children may be unab"e to express mental reference the way 4-year-olds do because of linguistic deficiencies. If this is so, the young child's ability may be underestimated.

Second, there are some instances of mental expressions for which it is very hard to assign a functional code with certainty. For example, a child sees a person recover his coat from a closet and says "He remembered his coat." In such cases, it may be impossible to tell whether the child is referring to a mental state (the retriever's remembering) or tu the correlated act of successfully finding the coat. With no way to distinguish between the two possibilities, the best a coder can do is to be consistent about the category to which such utterances are assigned. Gelman and Shatz coded such utterances as instances of mental reference. To the extent that such instances are commentaries on behavior (finding) and not genuine expressions of mental state (remembering), the frequency of mental state expressions would be overestimated. With 4-year-olds, potential overestimation is not a serious probiem because a second method supports the interpretations from natural language use. An experimental study which carefully varied the factors of behavioral outcome and knowledge state has shown that 4-year-olds can go beyond reference to overt performance in their use of remember, know, and guess (Johnson and Wellman, 1980). As an example, in a trick condition, children who had previously seen an item hidden insisted that they knew where it had been concealed even though their attempts to find the object were admittedly unsuccessful.

However, younger children's responses in such experimental tasks are uninformative: young children often simply answer indiscriminately, using the focal term in all possibilities and/or saying "yes" to everything (Misciones, et al., 1978; Wellman and Johnson, 1979). Hence, while the two different methods (form-function analysis of natural speech and experimental tasks) provide converging evidence on the abilities of children aged four and older, the problem remains of how to assess accurately the knowledge of still younger children.

In addressing this problem, we have modified and extended the Gelman and Shatz method of analyzing naturally occurring speech. To minimize the overestimation of the child's knowledge, we have limited to a greater extent 
the kinds of utterances classed as mental state expressions by creating additional separate functional categories for utterances such as references to action (as in the earlier remember example). (See Function Codes below.) Further, we also examined those utterances that were classed as mental state expressions to identify those in which the child-speaker spontaneously contrasted reality and nonreality, action and intention, and fact and belief. (See Contrastives below.) While such explicit contrasts are not the only instances of mental terms which can be taken as indications of understandings of mental state, we take them to be especially informative cases because the recognition that mental events can be at variance with observable events seems to be a core element in understanding the internal world. Indeed, making the difference explicit seems to be a prime motivation for expressing mental states among adults. These sorts of contrastive utterances, then, constitute a paradigm case of mental state expression, and they would be good evidence that the young child's conception of the internal world is similar at least in one way to the adult's. To the extent that they occur in a coded corpus of mental state expressions, we have assurance that we are not overestimating the young child's ability. In sum, we are conservative about what we code as mental state expressions, and we further consider how many of the instances so identified are paradigmatic contrastive cases.

The underestiniation problem concerns the issue of whether the expression of mental reference is masked or delayed by linguistic deficits. That is, one can ask whether there is evidence that children might have a concept of mental life but have difficulty with the linguistic forms used to express it, or whether there is evidence that the requisite linguistic skill is available for expressing mental reference before it actually appears. To address this question, we have examined the kinds of syntactic constructions used to express mental state and then looked for evidence of their productivity elsewhere. To the extent that the syntactic forms most associated with the expression of mental state do not appear to be readily available to the child, then there would be evidence that reliance on linguistic measures may underestimate the child's understanding of the mental world. On the other hand, if there are no deficiencies with the requisite structures, then the use of linguistic measures would be more justifiable.

To summarize, we use a multi-pronged method to investigate the early use of mental terms in the natural language of very young children. We identify the occurrence of mental terms, we utilize a revised form of the Gelman and Shatz coding system to distinguish clearly conversational from potentially mental uses of such terms, and we identify instances of contrastives within the category of mental state expressions. Finally, we assess the syntactic competence of our subjects with regard to their linguistic preparedness for producing expressions of mental state. 
We report two studies. First and primarily, there are analyses of longitudinal data on one child, from age 2 to 4 years. Next, confirmation of the basic patterns in the crucial first stage of the production of mental terms is sought by analyzing samples of speech, from 30 additional 2-year-olds.

\section{Study 1}

\section{Method}

\section{Data collection and transcription}

Samples of one child's spontaneous speech from age 2 years; 4 months to $4 ; 0$ were examined. The subject was a white, middle class male child (Abe) of graduate student parents. These samples have been analyzed elsewhere for other purposes (e.g., Kuczaj and Maratsos, 1975). There were 157 samples during the 20 month period reported here. Each sample represented 20 to 30 minutes of conversation gathered approximately twice a week at meal or playtimes when the child was interacting with one or both parents. On rare occasions other adults or children were present. Samples were transcribed using standard English orthography. Sentence fragments which were not false starts were counted as separate utterances, as were one word utterances.

Table 1 presents all mental terms which were identified in the transcripts. Only words such as remember, think, know and dream. which might in adult usage refer to higher level cognitive processes, were included in this study. No attempt was made to characterize the use of other sorts of words to refer to mental states. Analyses were then performed only on verbs since noun and adjective forms occurred very rarely; $95 \%$ of all mental terms identified were verbs.

The transcripts were grouped in two ways for analysis. The first was into 20 monthly segments. Considering the data at this level provides the detail necessary for determining the order of first occurrences of terms and functions. However, given the infrequency of mental verb use relative to the sample sizes, we grouped the data into four 5-month blocks for most other analyses.

\section{Function codes}

Utterances containing one or more mental verbs were categorized according to a modified version of a code developed by Gelman and Shatz. (1977). This code characterized the function of mental terms in the conversation, consid- 
Table 1. Mental words used by Abe

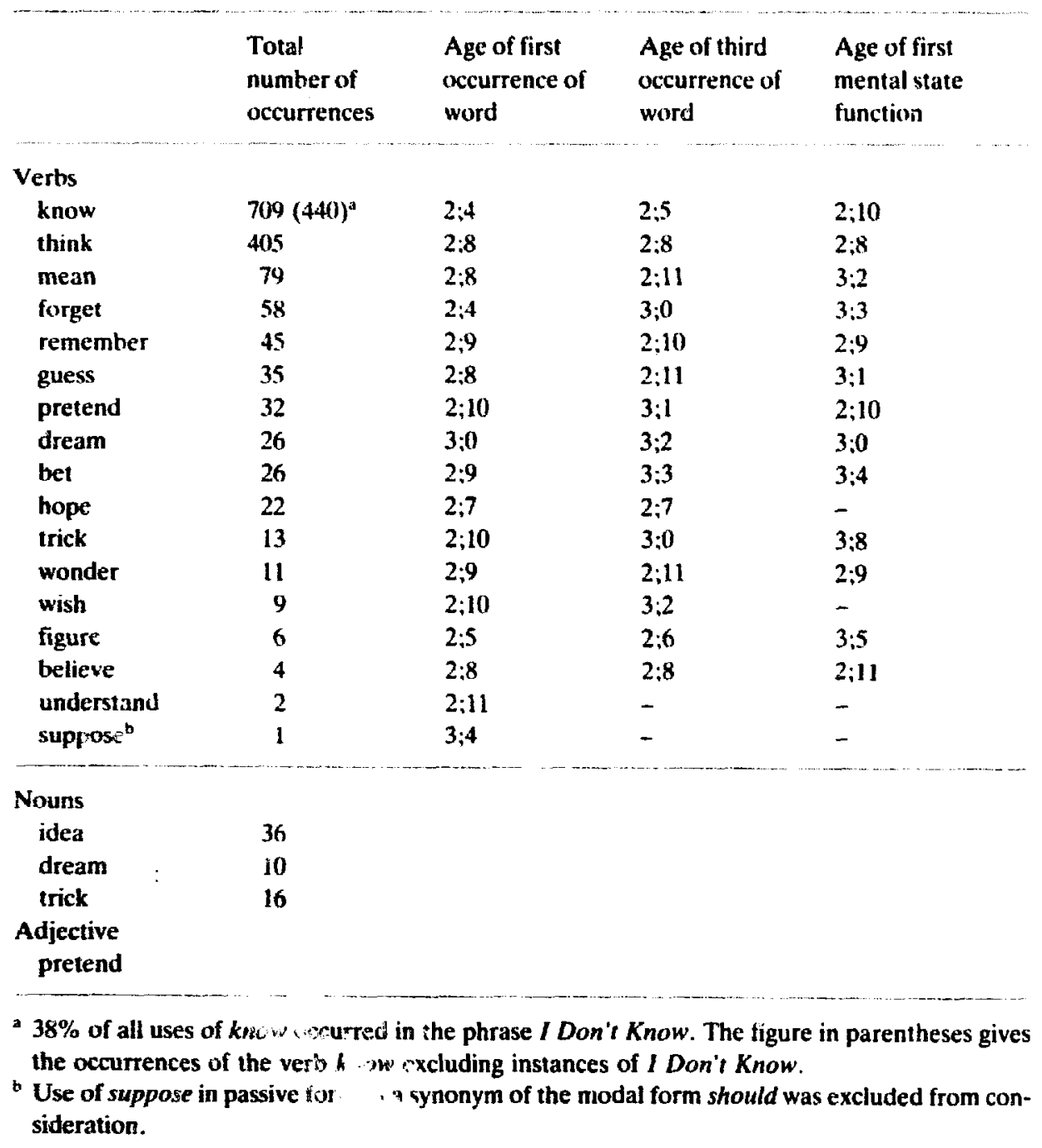

ering the context of the ongoing interaction. The coder interpreted the child's meaning of the utterance by considering what generally seemed to be happening in the interaction and the meaning of the sentences preceding and following the sentence with a mental verb. In assigning codes, the coder often paraphrased the mental expression to help determine the function of the word in the utterance. Then the paraphrase would be examined in relation to context to determine whether it was appropriate. For example, "I think" in "It's a ball, I think", would be paraphrased as "maybe." (See Gelman and Shatz, 1977, for further discussion of the general coding procedures.) 
If the child's meaning was unclear, the utterance was judged to be indeterminate, as were those instances for which more than one interpretation could be assigned equally appropriately. Approximately $10 \%$ of the utterances with mental verbs were coded as indeterminate and excluded from further analysis. Other utterances excluded from further consideration included sentence fragments and exact repetitions of a child's own utterance. For example, "I know that" said four times without interruption, was coded only once. Direct responses to parental requests such as "I think it's in the drawer" in response to the question "Where do you think it is?", were also excluded since mental verbs may have been used only to maintain discourse coherence from speaker to speaker without serving any further mental function. In all, functions were coded for $89 \%$ of Abe's utterances which contained a mental verb.

Codable utterances were sorted into seven categories. The first four categories, with the exceptions noted below, use definitions from Gelman and Shatz. The remaining three categories represent refinements on the initial set.

(1) Mental State. An utterance is classified as Mental State only if the mental term is judged, with regard to its context, to refer to the thoughts, memories or knowledge of the speaker, listener, or a third persori. Examples are: "She doesn't know all this" (referring to an absent child) and "I didn't, 'cept I tricked you." Because one never has direct access to another's thoughts, the determination of what is genuinely a reference to a mental state is of course open to some question. For example, one could argue that the child who said, "I didn't, 'cept I tricked you" was not referring to a belief state but was merely correcting himself. However, the context of the child's remark suggests that the child was more likely using the verb trick in reference to his father's understanding of the preceding interchange, which had gone as follows:

F: Did you have any dreams last night?

C: No, I didn't have any dreams at all.

F: Oh.

C: I didn't, 'cept I tricked you. I did have dreams.

Similarly, context helps classify "She doesn't know all this." It is more likely that utterance was a reference to another child's mental state rather than to task failure because the child in question was absent from the room. If the child in question had been in the room and failing at a relevant task, then one could argue that the utterance merely expressed the fact of failure. In the absence of a simultaneous perception of failure, that alternative becomes 
less viable. Classification of an utterance as an expression of mental state, then, depends on that classification being the most plausible interpretation given what is known about both the linguistic and the nonlinguistic context.

(2) Modulation of assertion. These utterances mark the degree of certainty with which a speaker makes an assertion. They can either sirengthen the assertion, as in "I know this fits too" (after being challenged) or weaken it, as in "I think this is a lamb" (in response to "What's this?").

(3) Directing the interaction. Utterances in this category focus the conversation or are used in a general way to aid interaction: Examples include attempts to (a) gain attention, e.g., "It's a hat, you know", (b) introduce or get information, "Know what?", "Remember where the dirt is?" and (c) introduce an activity "I thoughted we'd eat some cake" or "I guess I'll go for a ride."

(4) Clarification. Utterances in this category clarify the child's or another's utterance, or ask for clarification. An example of a clarification would be: "I mean the other one." Clarifications also took the form of repairs, for example, "It's a hat, I mean, a scarf."

(5) Expression of desire. Utterances expressing a desire via the use of a mental term such as hope or wish were coded separately because they of ten seemed to be paraphrasable by want statements. Expressions such as "I hope we have popcorn" would have been coded as Mental State in the Gelman and Shatz code but not in the present scheme.

(6) Action-memory. When verbs of memory or knowing were used clearly to refer to actions or the omission of an action, they were coded as actionmemory. An example would be "Don't forget mine home," said by Abe to urge his parents to bring along a toy house on a trip. Such uses seemed to be neither references to mental state nor attempts to direct an interaction. Rather, they often seemed to be prompts or reminders about action on the part of the hearer.

The coding of expression of desire and action-memory utterances separately from the Gelman and Shatz categories serves to make the present code both more specific and more conservative with regard to what gets counted as an expression of mental state.

(7) I don't know. The phrase I don't know, without a predicate complement, occurred often in Abe's speech. In many instances, especially early ones, this appeared to be merely an idiomatic negative expression. A variety of interpretations of this phrase were virtually always possible. Thus, all instances of I don't know were separated into this one category. (Gelman and Shatz examined only utterances longer than four words in length and so did not deal with such utterances.) 


\section{Additional codes}

\section{Contrastives}

Contrastives are those sentences which mark an understanding of a difference or discrepancy between some mental state and present or observable reality. In the utterance, "Before I thought this was a crocodile; now I know it's an alligator", a prior belief is explicitly contrasted with the current state of affairs. "I'm just pretending" in response to the question "Are they really dead?" is an explicit reference to reality or lack of it. References only to lack of knowledge, e.g., "I didn't know you went to the store" were not coded as contrastives nor were utterances made during fantasy play or lies (e.g., "I think we went to the moon yesterday"). Because the identification of contrastives is an important component of our method, we present here several further examples: "I was teasing you; I was pretending 'cept you didn't know that." "The people thought Dracula was mean, but he was nice." "I thought there wasn't any socks, but when I looked I saw them."

\section{Initiation}

We have already noted that ntental verbs which appeared to be exact repetitive conversational responses were not considered for additional analysis. To determine further how spontaneous the use of mental verbs was, we noted whether the child's use of a mental verb was (a) the initial use of that mental word in a sequence of conversation, (b) a repetition of the child's own use of the word in that same turn or in a previous turn, or (c) a repetition of the parent's use of the word in the previous two turns.

\section{Form coding}

Utterances containing mental verbs were also categorized in two ways. according to syntactic criteria. First, a distinction was made between simple and complex utterances, with the former having one verb phrase ("I know it") and the latter having more than one ("I think he knows it"). The second characterization was derived from the work of Shatz and Gelman (1973). They showed that mental verb use often occurs in complex sentences with predicate complements (e.g., "I think that the car is broken.") Following Shatz and Gelman, complex utterances with complement constructions were characterized in three ways according to the type of predicate complementizer produced: (1) that-complementizers ("I thought that it was hard"), (2) whcomplementizers such as what, how, and when ("I know what he wants"), and (3) to constructions ("I forget to look"). 


\section{Reliability of codes}

Two hundred and thirty-eight utterances including a variety of mental words were independently coded by two coders. The coders agreed on $84 \%$ of their codings for the function categories. On those individual words for which there were at least five tokens coded by both coders, agreement ranged from 75 to $93 \%$. Agreement scores were also computed for each coding category separately. Agreement on the mental state category was $84 \%$. Scores on other categories ranged from $71 \%$ for action-memory to $100 \%$ for clarification. There was $100 \%$ agreement for the contrastive and initiation codings.

\section{Results}

Frequency and variety of mental verbs

Of the 30.160 total utterances in the transcaipts, there were 1483 mental verb utterances. Of these, 144 were judged indeterminant, i.e., uncodable. In all, utterances containing codable mental verbs increased linearly from $1 \%$ of all utterances in the first time period to $8 \%$ in the fourth. Mental verbs increased in variety as well as in frequency from the use of two different mental verbs in the first month of the transcripts to 11 different verbs in the last month.

Table 1 shows that verbs varied widely in the frequency with which they occurred. Know and think were the most frequent, comprising $48 \%$ and $27 \%$ respectively of all mental verbs used. Some other verbs appeared only sporadically throughout the transcripts (e.g., figure, understand), whereas others appeared rarely at first and then more consistently (e.g., bet). because of this, the first appearance of a mental word may not necessarily provide a good indication of the time when a word was firmly established in Abe's lexicon. Thus, Table 1 charts the age at which each verb had been produced three times as well as the age of initial occurrence.

\section{Function analyses}

\section{Mental state function}

Table 1 shows that the earliest use of a mental verb to express a mental state function occurred at age $2 ; 8$, during the last month of the first time period. In that month, the verb think was used 3 times to express mental state. Table 1 also shows that 13 of the 17 verbs observed throughout the study were used at one time or another to express mental state. Only one verb, wonder, was used exclusively for mental state functions. All other verbs 
were sometimes used for other functions, although pretend (31 mental instances, 1 nonmental) and dream (22 mental, 3 nonmental) were used primarily to express mental state and guess was used primarily for nonmental functions ( 3 mental, 31 nonmental). For 8 of the 13 verbs, first uses were of the nonmental variety, these 8 include think, the first vert used for a mental state function.

\section{Variety, frequency and order of functions}

Table 2 shows that in the first 5 -month period Abe used mental verbs to express all possible functions. Despite the early occurrence of all functions, the modal function expressed changed from 'I don't know' in the first time period to expression of mental state in the fourth period. Closer analysis of the first time period on a month-to-month basis confirms an order of acquisition of function that is suggested by the frequency data in Table 2 . As shown in Table 3, the first month's transcripts contained the earliest occuriences of a mental verb, namely know in the standard phrase, I don't know. With the exception of a single use of forget, this is followed by use of know and figure in Directing the Interaction (e.g., "you know", "know what?"). Mental State and Modulation of Assertion functions both appear 2 months later and involve the verb think. (At this same time think is also used for Directing the Interaction.) In short, there is good evidence that Abe's first uses of mental verbs involved either the idiomatic phrase $I$ don't know or pragmatic social routines used to focus and direct the conversation. The func-

Table 2. Functional uses of mental verb utterances at the different age periods

\begin{tabular}{|c|c|c|c|c|}
\hline \multirow{2}{*}{$\begin{array}{l}\text { Proportion of mental verb } \\
\text { utterances }^{\text {a }} \text { classified into }\end{array}$} & \multicolumn{4}{|c|}{ Age period } \\
\hline & $2 ; 4-2 ; 8$ & $2,9-3 ; 1$ & $3 ; 2-3 ; 6$ & $3 ; 7-3 ; 11$ \\
\hline Mental State & $0.04(3)^{b}$ & $0.23 \quad(79)$ & $0.28(118)$ & $0.43(208)$ \\
\hline Expression of Desire & $0.03 \quad(2)$ & $0.03 \quad(10)$ & $0.05 \quad(21)$ & $0.01 \quad(7)$ \\
\hline Modulation of Assertiun & $0.09 \quad(7)$ & $0.11 \quad(39)$ & $0.07 \quad(29)$ & $0.06 \quad(29)$ \\
\hline Directing the Interaction & $0.18(14)$ & $0.27 \quad(91)$ & $0.30(125)$ & $0.36(17.4)$ \\
\hline Clarification & $0.01 \quad(1)$ & $0.02 \quad(6)$ & $0.07 \quad(29)$ & $0.05 \quad(25)$ \\
\hline Action-Memory & $0.01 \quad(1)$ & $0.01 \quad(4)$ & $0.03(12)$ & $0.03 \quad(1+4)$ \\
\hline I Don't Know & $0.65(51)$ & $0.31(106)$ & $0.20 \quad(84)$ & $0.06 \quad(24)$ \\
\hline
\end{tabular}

a Mental verb utterances here exclude indeterminate utterances. There were 83 rotal mental verb utterances in the first period, 387 in the second, 473 in the third, and 540 in the fourth. Proportions are based on the codable mental verb utterances, which numbered $79,335,418$. and $\mathbf{4 8 5}$ in the four successive time periods.

b Numbers in parentheses show the absolute frequencies of various categories. 
Table 3. Time 1 functions and mental verbs by age of occurrence

\begin{tabular}{|c|c|c|c|c|c|c|c|}
\hline Age & $\begin{array}{l}\text { I Don't } \\
\text { Know }\end{array}$ & $\begin{array}{l}\text { Action- } \\
\text { Memory }\end{array}$ & $\begin{array}{l}\text { Direct. } \\
\text { Interaction }\end{array}$ & $\begin{array}{l}\text { Express. } \\
\text { of Desire }\end{array}$ & $\begin{array}{l}\text { Mental } \\
\text { State }\end{array}$ & $\begin{array}{l}\text { Modulat. } \\
\text { of Assertion }\end{array}$ & $\begin{array}{l}\text { Clari- } \\
\text { fication }\end{array}$ \\
\hline $\begin{array}{l}2: 4 \\
2 ; 5\end{array}$ & $\begin{array}{l}\text { know" } \\
\text { know }\end{array}$ & forget & & & & & \\
\hline $2: 6$ & know & & $\begin{array}{l}\text { know }^{a} \\
\text { figure }^{a}\end{array}$ & & & & \\
\hline $2: 7$ & know & & know & hops & & & \\
\hline$?: 8$ & know & & $\begin{array}{l}\text { know } \\
\text { think } \\
\text { guess } \\
\text { believe }\end{array}$ & & think' & think $^{\mathrm{a}}$ & mean \\
\hline
\end{tabular}

Age by which a verb had occurred at least three times in a particular function.

tions Mental State and Modulation of Assertion occur late in the first time period and relatively co-temporaneously.

Verb by function analyses

There was little indication that particular words were associated primarily with one function. Many different verbs were used to express the most frequent functions. For example, 10 different verbs were used for Directing the Interaction, 13 for Mental State, and 8 for Modulation of Assertion. Only the Expression of Desire, Clarification, and Action-Memory functions were expressed almost exclusively $b_{y}$ one on two verbs (hope and wish, mean, and forget, respectively). Typically, verbs that were eventually used for a varis ty of categories were recruited for a variety of functions rather early on in the ir existence in the lexicon. For example, think was used for three different functions in the first time period and even know and guess, which served only one function each during the first time period, partook of as many differerit functions in the second time period as they did in the fourth (four for know and three for guess).

\section{Contrastive utterances and initiations}

Contrastives-utterances that make explicit reference to a discrepancy between internal states and reality-are considered an important source of evidence that the young child has of w un to characterize mental states as different from overt reality. Contrastives xomprised $20 \%$ of all utterances expressing mental state functions in the second time period, $31 \%$ in the third, and $20 \%$ in the fourth period. Even in the first period, two of the first three mental 
state utterances were contrastives referring to differences between prior mental states and actuality. Thus, our first instances for Mental State both seem more plausible in context than other codings and share commonalities with paradigmatic adult expressions of mental state.

As for the degree to which the child's use of mental terms was self-initiated, only $10 \%$ of the observed uses of mental verbs immediately followed use of the verb by a parent. Seventy-five percent of the time the child's use was the first occurrence of the verb in the conversation, and $15 \%$ of the time the child's use followed a prior use by the child himself. There were no important differences in the proportion of these types of initiation for Mental State versus the nonmental functions. This substantiates that mental state utterances were not mere imitations of parental speech.

\section{Form analysis}

\section{Complexity}

From their earliest occurrences, mental state utterances were more likely to be complex (i.e., contain more than one verb phrase) than simple. "Think of things" is an instance of a simple mental state utterance, whereas "I thought they were called strawberries" is an instance of a complex one. Seven of the first ten mental state utterances were complex, as were all three uses occurring in the first time period. In contrast, only $40 \%$ of the utterances expressing nonmental functions in that time period were complex. Across all time periods, mental state utterances were somewhat more likely to be complex than were nonmental utterances using mental verbs ( $72 \%$ versus $60 \%){ }^{1}$

Occurrence of complement constructions expressing nonmental functions

Abe's earliest utterances expressing mental state involved all three types of predicate complementation described earlier. To determine whether Abe was capable of producing such complement constructions before the first appearance of mental state utterances, we examined the transcripts prior to the first occurrence of mental state functions for instances of the various types. We found 22 instances of utterances with wh complements ("Show mie how to work this."), 15 with that complements, expressed or implied, ("I guess (that) I'll have a bobber".), and 32 with to constructions ("I tried to eat it all"). In fact, 20 of the wh constructions, 7 of the that constructions,

\footnotetext{
'Despite relative complexity differences, neither utterances expressing mental state nor those expressing other functions exhibited much disfluency (as in. "I think ... I think that's a pig"). Only $3 \%$ of all mental verb utterances were disfluent.
} 
and 25 of the to constructions occurred more than a month before the first mental state expression, and instances of all three constructions were present from the first month of the transcripts. Moreover, "etter than 40 of the 69 instances of early complementation included a mental verb in a nonmental conversational function (such as the "guess" example above). In short, Abe had considerable experience with the vocabulary and syntax common to expressions of mental state before he began to produce such expressions. There seems to be no evidence that Abe's production of utterances expressing mental state was delayed by a lack of lingtistic skill.

\section{Summary}

Mental verbs were present in Abe's speech as early as 2;4. Nevertheless, both the frequency and variety of mental verbs increased over time. Such verbs were first found in idiomatic or conversational phrases, but soon thereafter they began to serve a wider variety of functions, with mental state expressions making their first appearance by 2;8. Contrastives were among the first mental state utterances. As for the necessary linguistic skill to produce utterances expressing mental state, Abe apparently had that skill well in advance of his first observed productions of mental state function.

\section{Study 2}

Study 1 involved an extensive examination of one child's early mental verb use. To corroborate the results of that intensive study, we examined language samples from $\mathbf{3 0}$ additional children, using the same sorts of codes applied to Abe's data. Since our primary concern was to verify the early appearance of Mental State utterances, the subjects corresponded closely in age and MLU to Abe at the time of his early transcripts.

\section{Method}

The data come from 15 male and 15 female children who had participated in a longitudinal study of language development (Hoff-Ginsberg, 1981). Each child was to have been observed at home in interaction with his or her mother on four different occasions at 2-month intervals. Twenty-nine, twenty-four and twenty-two mother-child dyads participated in the second, third, and fourth visits, respectively. At each visit a 20 to 30 minute sample of dialogue occurring spontaneously during play with toys was audio-recorded and later 
transcribed. At the time of the first visits, the children ranged in age from $2 ; 0$ to $2 ; 6$, with a mean MLU of 2.04 (S.D. $=0.43$ ). At the final visits, age ranged from 2;6 to 3;0 and MLU averaged 3.31 (S.D. $=0.62$ ). The average age of the subjects during the 6 month period $(2 ; 2$ to $2 ; 8)$ is comparable to Abe during Time Period $1(2 ; 4-2 ; 8)$. Abe's MLU during the last session of that time period was 3.81 , well within one S.D. of the larger sample's mean of 3.31. All child utterances from all four sessions were coded following the procedures described in the first study.

\section{Results}

\section{Frequency analyses}

As a group, the children in Study 2 produced utterances containing a mental verb at a rate roughly comparable to Abe in Time $1 .{ }^{2}$ Across all four sessions, 151 of their 17,494 utterances, or slightly less than $1 \%$, contained a mental verb, compared to $1.4 \%$ of all Abe's Time 1 utterances. Moreover, the choice of particular verb was also comparable. Know accounted for $74 \%$ and think $15 \%$ of the mental verb instances of Study 2 children and $66 \%$ and $16 \%$ respectively for Abe at Time 1.

\section{Function analyses}

\section{Mental State function}

Again the rate and timing of mental state productions are comparable to Abe's data. For Study 2 children, seven of the 138 codable mental verb utterances (5\%) expressed mental state; for Abe at Time 1, 4\% did. All seven of the mental state utterances occurred in the last session, when the six children producing them ranged in age from $2 ; 6-2 ; 8$. Abe's three Time 1 Mental State utterances occurred in the last month when he was $2 ; 8$. Study 2 children produced two contrastives. One difference between Abe's productions and those of Study 2 children was in the choice of verb to express mental state. Abe's first mental state utterances all used think: Study 2 children used know five times and forget twice.

\footnotetext{
${ }^{2}$ Seven of the 30 children produced no mental verbs at all in any of the sessions. Nothing (age or MLU) particularly distinguished these seven children from the others. We cannot say whether these children were just a bit slower to produce such constructions or whether sampling procedures account for the lack of instances in these data.
} 
Variety, frequency, and order of functions

With the exception of Expression of Desire, Study 2 children used mental verbs for all of the functions expressed by Abe during Time 1, and with comparable frequency. $56 \%$ of their mental verb utterances were coded as $I$ don't know, $24 \%$ were Directing the Interaction, $12 \%$ were Modulation of Assertion, $1 \%$ were Action-Memory, and $1 \%$ were Clarification (Abe's comparable Time 1 figures appear in Table 2.)

As for order of occurrence, of the 23 children who produced at least one spontaneous mental verb sometime during the study, the first use for 11 children was I don't know, and for 8 others it was Directing the Interaction. Four others produced more than one function in the first session in which a mental verb appeared. For all four of these children, at least one of the uses was either I don't know or Directing the Interaction.

As in Abe's data, there was a strong indication that Directing the Interaction precedes Mental State uses. All six of the children producing Mental State uses in the last session had produced Directing the Interaction utterances previously. Also consonant with Abe's data was the lack of any consistent ordering between the Modulation of Assertion and Mental State functions. By the fourth session, the former had appeared in two children's speech, and the latter in the speech of five children. One child began to use both in the same session.

\section{Form analyses}

Similar to Abe's data, early Mental State utterances in this sample included simple sentences (e.g., "Kitty know") and more complex forms involving predicate complementation (e.g., "Someone know how a truck goes"). Of the seven Mental State utterances, five involved predicate complementation (four $\boldsymbol{w h}$-complement forms, one to-construction). Again a consideration of the children's productions prior to their first uses of Mental State function confirms the claim that lack of linguistic skill alone cannot account for the dearth of Mental State expressions. Of the six children who used mental verbs to express Mental State meanings, all used at least one form of predicate complementation in their preceding sessions; four of the six used at least two forms. Of the 17 children who produced mental verbs but no Mental State utterances during the course of the study, all used at least one type of predicate complementation for other purposes, 13 used at least two types and 8 used all three. Thus, all of the 23 children had at least some competence in predicate complement construction, to say nothing of their ability to use their vocabulary in simple sentences to express Mental State (e.g., Kitty know). 


\section{Summary}

The Study 2 children were similar to Abe at the comparable age. No children were observed using mental verbs to express Mental State before the age of $2 ; 6$. All children used mental verbs to serve at least the Directing the Interaction function before they used them for Mental State. Six of the children in this study produced at least one Mental State expression at about the same age as Abe began to produce them, and two of these were contrastives. Finally, the children exhibited at least some ability to produce the kinds of syntactic constructions often used to express Mental Statc. This argues against the possibility that even earlier appearance of Mental State expressions is blocked by linguistic deficits.

\section{Discussion}

Our study has revealed several important aspects of the development of $m$. $n$ tal reference. First, consider simply the use of mental terms regardless of function. Mental verbs begin to find their way into the child's speech during the third year of life. In Abe's data, mental verbs were present, although extremely rare, in the earliest transcripts (age $2 ; 4$ ); in the second study, the average age of the seven children using any mental verbs in their first session was $2 ; 2$. From this start, frequency of mental verb use increased for both Abe and the sample of 30 children. In all, 24 of the 31 two-year-olds we observed produced at least one mental verb during our studies. Thus, the ages of first occurrence of mental verbs observed here are consistent with reports of other investigators (Bretherton, et al., 1981; Limber, 1973).

Mental verbs are not first used to refer to internal mental states or processes, however. Our functional analysis revealed that all seven children who ultimately produced a mental reference had previously used mental verbs with at least the Directing the interaction function. It is essential, therefore, if the child's language is to be a measure of his understanding of mental life, to go beyond a tally of the mere production of particular words to an assessment of the semantic: and pragmatic functions of those words.

In this regard one important aspect of our findings concerns the uscfulness of our method for determining the time at which the understanding of mental state is demonstrable. Using a conservative functional code along with an analysis of contrastives, we were able to identify with confidence early occurrences of mental state expressions. Indeed, for some of our subjects the first occurrences of mental reference lag behind other uses of mental verbs by only a few months. To date, no experimental methods have been successful 
in eliciting as clear a display of this sort of knowledge in such young children.

Moreover, our findings suggest that our method is not overly conservative. Since the method is linguistically based, it is open to the criticism that children might have had understandings about internal mental states which they could not express linguistically. However, we found no evidence that linguistic deficits might have generally blocked even er-lier production of mental state expressions. There was ample evidence that both the lexical items and the complex forms typically used to express mental state were readily available to most of the children in advance of their being employed in mental reference. It seems unlikely, then, that the children would have had an understanding of mental state but simply could not refer to it in their natural speech. Therefore, natural language data, when analyzed appropriately with regard for both form and function, provide a viable tool to access information about the child's understanding of the internal world.

Related to the question of when reference to mental state first occurs is the question of whether such reference is reserved for one's own mental states or whether early instances refer to the states of others as well. The issue is particularly relevant to the child's status as a communicator because it has been argued that the understanding that one's interlocutor has beliefs, thoughts, and goals is a necessary basis for true participation in mature human communication (see Dennett, 1978; Shatz, 1983; in press). The data from our two studies are equivocal on this issue. Whereas reference to others' mental states did not appear in Abe's data until three months after the first appearances of self-reference, three of the six children in the second study produced as their single instances of mental state function, references to mental states other than their own. Since these data are limited in quantity, they are not definitive, but at least they suggest that once mental state expressions do start to appear, their domain of reference is not limited to the self for very long, if at all.

One final issue deserving discussion is the question of possible precursors for the various functions; in particular, the possibility that knowledge of some functions for mental verbs facilitates acquisition of other functions. A striking fact in the data is that all children producing Mental State utterances had previously produced mental verbs to direct the interaction. This consistent use of mental verbs for conversational functions prior to the expression of mental state is especially interesting in light of the etymological relations often assumed for such functions. Conversational functions are presumably derived by emphasizing selected aspects of the semantic descriptions of certain lexical items. For example, the use of think to express uncertainty (as in Modulation of Assertion) takes advantage of the fact that the English verb think is not a factive. That is, the propositional contents of the mental act of 
thinking are not necessarily true. Since declarative utterances unmarked by performatives are taken to be assertions of truth (e.g., It's raining out), marking an utterance with $I$ think implies a movement away from that assertion (I think it's raining out). Likewise, explicitly marking an utterance with a factive (as in I know it's raining out) emphasizes or focuses on the assertion of truth. In this stnse the conversational function Modulation of Assertion is said to depend on the semantic descriptions entailed by certain mental verbs as they are found in expressions of mental states (see Urmson, 1963). Thus, in terms of semantic etymology, Mental State is a precursor for conversational functions. Yet, the order of the children's productions is reversed, with at least some conversational functions occurring earlier than the Mental State function.

By one account, the reversal in the child's order of acquisition would be superficial. Several pieces of data argue for this position. For one, there seems to be very little productivity in the earliest uses of mental verbs for conversational functions. Most of the erirliest conversational productions involve the stereotypic forms, Know what? or I don't know. In Abe's data, for example, productivity with a range of lexical items was not demonstrated for the earliest function, Directing the Interaction, until about the same time the Mental State function appeared. Also, the more subtle conversational function Modulation of Assertion does not consistently precede Mental State. These data suggest that early conversational uses are merely rote-learned expressions. Whether children's knowledge becomes organized later according to the semantic bases suggested by the etymological accounts remains an open question, however. In our data, there was no support for this possibility either. For example, Mental State did not regularly precede Modulation of Assertion. Thus, it would be premature to conclude the early mental verb uses observed in our data either bear no relation to later knowledige or that they produce strong facilitation for the acquisition of Mental State understanding. Further research should investigate the question of whether some functions are facilitative precursors of others.

In summary, the present research into the child's reference to mental events describes the early development of an ability to distinguish and communicate about the internal world of thoughts, memories, knowledge, and dreams. Mental reference reflects a conceptual acquisition of great import. Here we have identified its tenuous but unmistakable beginnings. 


\section{References}

Bretherton, 1., McNew, S., and Beeghly-Smith, M. (1981) Early person knowledge as expressed in gestural and verbal communication: when do infants acquire a "theory of mind"? In M. Lamb and L. Sherrod (Eds.), Social Cognition in Infancy. Hillsdale NI, Erlbaum.

Broughton, J. (1978) Development of concepts of self, mind, reality and knowledge. In W. Damon (Ed.), New Directions for Child Development. San Francisco, Jossey-Bass.

Clark, E.V. (1978) Strategies for communicating. Child Devel. , 49, 953-959.

Dennett, D.C. (1979) Brainstorms. Sussex, Harvester Press.

Gelman, R., and Shatz, M. (1977) Appropriate speech adjustments: the operation of conversational constraints in talk to two-year-olds. In M. Lewis and L. Rnsenblum (Eds.), Interaction, Conversation and the Development of Language. New York, Wiley.

Johnson, C.N., and Wellman, H.M. (1980) Children's developing understanding of mental verbs: remember, know, and guess. Child Devel., 51, $1095-1102$.

Kuczaj, S.A., and Maratsos, M.P. (1975) What children can say before they will. Merrill-Palmer Quarterly, 21, 89-111.

Limber, 1. (1973) The genesis of complex sentences. In T.E. Moore (Ed.), Cognitive Development and the Acquisinion of Language. New York, Academic Press.

Misciones, J.L., Marvin, R.S., O'Brien, R.G., and Greenberg, M.T. (1978) A developmental study of preschool children's understanding of the words 'know' and 'guess'. Child Devel., 48, 1107-1113.

Nelson. K., Rescorla, L., Gruendel, J., and Benedict, A. (1978) Early lexicons: what do they mean? Child Devel., 49, 960-968.

Piaget, J. (1929) The Child's Conception cy ire World. New York, Harcourt, Brace.

Shatz, M. (1983) Communication. In J.H. 'vell and E. Markman (Eds.), Cognitive Development, Handbook of Child Psychology, 4th ed. Nt w ork, Wiley.

Shatz, $M$. (In press) On transition, contin:;i and coupling: an alternative approach to communicative development. In R.M. Golinkoff (E0 ). The Transition from Prelinguistic to Linguistic Communication. Hillsdale, NJ, Erlbaum.

Shatz, M., and Gelman, R. (1973) The development of communications skills: modifications in the speech of young children as a function of listener. Monographs of the Socigty for Research in Child Development, $38,(5$, Serial No. 152).

Umuson, S. (1963) Parenthetical verbs. In C.E. Caton (Ed.), Philosophy and Ordinary Language. Urbana, IL, University of Illinois Press.

Wellman, H.M. (In press) The child's theory of mind: the development of conceptions of cognition. In S.R. Yussen (Ed.), The Growth of Reflection. New York, Academic Press.

Wellman, H.M., and Johnson, C.N. (1979) Understanding of mental processes: a developmental study of remember and forget. Child Devel., 50, 79-88.

\section{Reference notes}

1. Gearhart, M., and Hall, W.S. Interzal state words: cultural and situational variation in vocabulary usage. Wothing paper no. 16. Laboratory of Comparative Human Cognition and Institute for Comparative Human Development. The Rockefeller University, August, 1978.

2. Hoff-Ginsberg, E. The role of linguistic experience in the child's acquisition of syntax. Unpublished Ph.D. discertation, The University of Michigan, 1981. 
Résumé

La capacité de refléchir et de cismmuniquer sur des croyances, connaissances, objectifs personnels ou altruistes est généralement considéré $\%$ nme la marque de la cognition humaine. Les débuts de cette capacité sont peu connus. Cela tient à l'absence de méthodes permettant de cerner evcc précision ces capacités chez les jeunes enfants. La capacité des jeunes enfants à refléchir sur des états mentaux ou les communi, Ler a été étudiée en utilisant une méthode d'analyses convergentes des énoncés prononcés en milieu naturel. ia première étude porte sur la fréquence et la fonction dans les productions d'un enfant de $2 ; 4$ à 4 ans, des veroes réferant à des états mentaux tels les verbes penser et savoir. Dans la seconde étude on examine des exemples plus courts recueillis durant une periode de 6 mois auprès de 30 enfants de 2 ans. Les données suggèrent que les verbes mentaux sont d'abord utilisés avec une fonction de communication plutôt que de référence mentale. Les premières utilisátions mentales commencent dans la deuxième mcitié de la troisième année. Ła plupart des enfants étudiés faisant preuve de la connaissance linguistique nécessaire pour référer à des états mentaux. on pense que l'absence de telles références est due au fait que les jeunes enfants ne sont pas conscients de tels états ou tout au moins qu'ils ne comprennent pas leur pertinence comme sujets de conversation. 